\title{
Next generation paramedics, agents of change, or time for curricula renewal?
}

This article was published in the following Dove Press journal:

Advances in Medical Education and Practice

8 November 2013

Number of times this article has been viewed

Brett Williams

Paul A Jennings

Chris Fielder

Amanda Ghirardello

Department of Community

Emergency Health and Paramedic

Practice, Faculty of Medicine,

Nursing and Health Sciences, Monash

University - Peninsula Campus,

Frankston, VIC, Australia
Correspondence: Brett Williams

Department of Community

Emergency Health and Paramedic

Practice, Faculty of Medicine, Nursing

and Health Science, Monash University -

Peninsula Campus, PO Box 527.

Frankston 3199, VIC, Australia

$\mathrm{Tel}+6$ I 399044283

Fax +6I 399044168

Email brett.williams@monash.edu
Background: Knowledge translation involves the dissemination and application of scientific research findings into clinical practice. In the health care arena, uptake of evidence-based assessment and intervention strategies is aimed at reducing inefficiencies and ultimately improving patient outcomes. However, numerous studies have purported gaps in knowledge translation in the health care professions. The objective of this study was to classify the traits of undergraduate paramedic students from Monash Univeristy, Australia, using the practice style inventory (PSI).

Methods: A cross-sectional study of students across all undergraduate years from Emergency Health and Emergency Health/Nursing was completed. Student knowledge translation levels were measured using the 17-item paper-based PSI.

Results: A total of 266 students participated in the study, of which $68.4 \%$ were females. The majority of participants were $<26$ years of age $(n=228)$ and just over half enrolled in second year studies $(n=134)$. Two subscales produced statistically significant differences: evidence versus experience (extent to which scientific evidence rather than authority is perceived as the best source of knowledge) and nonconformity (degree of comfort with clinical practices that are out of step with recommendations of leaders). There was a statistically significant difference between sex on the evidence versus experience subscale $(P<0.0001, d=0.51)$, and between year levels on the nonconformity subscale $(P<0.007, d=0.63)$.

Conclusion: This study identified several differences in knowledge translation subscales in the undergraduate paramedic cohorts. Further investigation is warranted in order to better understand barriers and facilitate improved uptake of evidence-based research into clinical practice and, ultimately, improve patient outcomes. Future research using a longitudinal study design to capture changing attitudes to knowledge translation in the postgraduate population may also prove valuable in curricula renewal.

Keywords: curriculum, knowledge translation, paramedic students, practice style inventory

\section{Introduction}

Health care systems globally are enduring the demanding challenge of improving the quality of care and reducing the risk of adverse events. ${ }^{1}$ Evidence drives improvements in patient care ${ }^{2}$ and efficient transference of evidence between universities and the clinical interface is vital to give the best possible care to patients. Unfortunately, providing evidence in the form of scientific journals, while necessary, is not all that is required for delivering best practice care to patients as health care systems often fail to use evidence optimally, resulting in inefficient practice and quality of life for patients. ${ }^{3-6}$ McGlynn et $\mathrm{al}^{5}$ found that adults in the US were treated with less than $55 \%$ of optimal recent evidence-based practice (EBP). Many expressions have been 
used to describe the process of putting health knowledge into practice; ${ }^{7}$ however, knowledge translation (KT) has become the commonly accepted term within the literature. ${ }^{8} \mathrm{KT}$ is the science of reducing the gaps present between knowledge and practice; the science of transferring information to where it is needed. ${ }^{9} \mathrm{KT}$ research is essential if the benefits of medical and health research are to be translated in clinical practice. It is necessary to improve health and quality of life of patients, and to enhance the productivity of the health care system. ${ }^{9,10}$

The Canadian Institutes of Health Research defines KT as:

a dynamic and iterative process that includes the synthesis, dissemination, exchange and ethically sound application of knowledge to improve health, provide more effective health services and products and strengthen the health care system. ${ }^{11}$

KT may be thought of as the transfer of knowledge from research into clinical practice, and it is ultimately about capturing and disseminating information and innovation to ensure its application. ${ }^{9,10}$ Since its inception, this definition has been accepted by some and adapted by other organizations around the globe including the World Health Organization and the US National Center for Dissemination of Disability Research. ${ }^{8,12}$

Efficiency in the uptake of evidence-based research is paramount in paramedic practice, as it is with other health care professions. It is important that evidence-based research is efficiently translated into paramedic practice as such strategies serve to improve patient outcomes and reduce system inefficiencies, thereby strengthening outof-hospital care and the broader continuum of health care. This will also help to achieve equity in health care delivery, thus improving access to the best possible standards in clinical care. ${ }^{9,10}$

In a bid to close the gaps in health care Wyszewianski and Green ${ }^{13}$ pioneered original research with a group of family physicians and general practitioners. They postulated that the gap in KT may be, at least in part, explained by observed differences between clinicians in what they consider to be credible sources of information, in their degree of comfort with stepping outside traditional practice, and in the weight they assigned to purely practical concerns. As such, Wyszewianski and Green proposed the use of the practice style inventory (PSI) to classify physicians against three traits. These are: the individual's belief in scientific evidence versus clinical experience and authority as the best source of knowledge about good practice; their willingness to diverge from common or previous practice, or the recommendations of leaders; and the importance attached to pragmatic concerns. Wyszewianski and Green, and Green et al held the view that the classification of clinicians using these three traits was highly important, as an individual physician's reasons for choosing or not choosing to implement various assessments and intervention strategies was ultimately a function of these three underlying factors. ${ }^{13,14}$ Others have since replicated this study in numerous other fields including nursing, occupational therapy, and physical therapy, among others. ${ }^{15,16}$ To our knowledge, there have been no studies conducted using an Australian undergraduate or graduate paramedic cohort.

In the paramedic discipline, understanding EBP by paramedics is as important as undertaking emergencymedical-services-related clinical trials. ${ }^{17}$ If clinicians do not understand EBP, they will never be accepting of, or assist in the translation of such evidence into practice. The primary objective of this study was to classify the traits of undergraduate paramedic students from Monash University, Australia, using the PSI. Addressing this objective will provide new knowledge in assessing the attitudes and acceptance of KT in a bid to gauge whether the undergraduate cohort, representative of the next generation of paramedics, are indeed agents of change.

\section{Methods}

\section{Design}

A cross-sectional study was carried out using a convenience sample of undergraduate paramedic students at Monash University, Australia, during semester 1, 2012.

\section{Participants}

Students were eligible to be enrolled in this study if they were enrolled in either the Bachelor of Emergency Health or the Bachelor of Emergency Health/Bachelor of Nursing double degree at Monash University. Monash University is one of five universities in Victoria, Australia that offers entry-level paramedic degree programs.

\section{Instrumentation}

Participants were asked to respond to a 17-item paper-based survey, the PSI, which uses a five-point Likert scale (where $1=$ Strongly Disagree and 5 =Strongly Agree). The 17 items contained in the PSI are designed to score an individual's tendency towards three main underlying traits. Six of these items, items $1,3,9,12,16$, and 17 , are aimed at identifying a clinician's attitudes towards evidence versus experience 
(minimum score 6 - maximum score 30 ). Six questions, items $2,5,7,11,13$, and 15 , gauge attitudes towards nonconformity (minimum score 6-maximum score 30 ). Finally, there are five questions, items $4,6,8,10$, and 14 , that assess an individual's focus on pragmatic concerns (minimum score 6-maximum score 25).

\section{Procedures}

At the conclusion of lectures for each of the undergraduate programs, students were invited to participate on a voluntary basis in this study. Students were provided with an explanatory statement and were informed that participation was voluntary and anonymous. The questionnaires took students approximately 15 minutes to complete and consent was implied by its completion and submission. No followups were undertaken. Ethics approval was obtained from the Monash University Human Research Ethics Committee.

\section{Data analysis}

The SPSS program (Statistical Package for the Social Sciences Version 20.0; IBM Corporation, Armonk, NY, USA) was used for data storage, tabulation, and the generation of descriptive and inferential statistics. Descriptive statistics including means and standard deviations (SDs) were used to summarize the demographic data. Inferential statistics, $t$-tests, and one-way analysis of variance, including post hoc tests, were used to compare the differences between age groups, sex, and year level. The effect sizes were used to evaluate the magnitude of the findings. Results were considered statistically significant if the $P$-value was $<0.05$; effect sizes (effect sizes $[d]$ were also calculated for quantifying the differences between mean scores) were also calculated for quantifying the differences between mean scores.

\section{Results}

A total of 266 students took part in the study out of a total eligible student population of 420 (63\% response rate), the majority of whom were female ( $n=179 ; 67.3 \%)$. Representation between double degree and single degree students was fairly even, with $51.1 \%$ enrolled in a double degree $(n=136)$ compared with $48.9 \%$ enrolled in the single degree program $(n=130)$. Half of the participants were in their second year of study $(n=134 ; 50.4 \%)$. Most participants were either less than 21 years of age $(n=119 ; 44.7 \%)$ or aged from 21 to 25 years $(n=109 ; 41.0 \%)$. There were fewer participants aged 26 years or older, accounting for just $14.3 \%$ of the sample. The full demographic profile is outlined in Table 1.
Table I Demographic distributions

\begin{tabular}{llll}
\hline Variable & Descriptor & $\mathbf{n}$ & Percentage (\%) \\
\hline Sex & Male & 81 & 30.4 \\
& Female & 179 & 67.3 \\
Age & Missing & 6 & 2.3 \\
& <2I years & 119 & 44.7 \\
& 2I-25 years & 109 & 41.0 \\
& 26-30 years & 21 & 7.9 \\
& $31-35$ years & 7 & 2.6 \\
Year level & $36-40$ years & 3 & 1.1 \\
& $41-45$ years & 3 & 1.1 \\
& $>45$ years & 4 & 1.5 \\
& Year I & 51 & 19.2 \\
& Year 2 & 134 & 50.4 \\
Course type & Year 3 & 76 & 28.6 \\
& Year 4 & 5 & 1.9 \\
& Single degree & 130 & 48.9 \\
& Double degree & 136 & 51.1 \\
\hline
\end{tabular}

The mean score for the six-item evidence versus experience subscale was 13.3 ( $\mathrm{SD} \pm 2.32$ ), the six-item nonconformity subscale mean score was 16.8 ( $\mathrm{SD} \pm 2.04$ ), and the mean score for the five-item pragmatic concerns subscale was 15.3 ( $\mathrm{SD} \pm 2.07$ ). The mean values for each item are provided in Table 2.

These data suggest that there was a statistically significant difference and large effect size between sexes on the evidence versus experience subscale $(P<0.0001, d=0.51)$ with female mean scores at 13.7 versus males at 12.5 . There was also an observed significant difference and large effect size between year levels on the nonconformity subscale $(P<0.007, d=0.63)$, with degree of comfort with nonconformity generally trending upwards as the study progressed and also trending upwards with increased age.

\section{Discussion}

To our knowledge, this is the first time a PSI has been conducted identifying the traits of an undergraduate paramedic cohort. The results, however, are consistent with the work conducted by Green et al and their multiple studies involving family physicians, interns, and other specialist groups, as well as the work of Korner-Bitenski et al on occupational therapists and physical therapist traits. ${ }^{13-16}$

Regarding the evidence versus experience subscale, the literature suggests that a subtotal score of greater than 22 indicates that the individual relies heavily on evidence. ${ }^{14}$ With a mean score of only 13.3 ( $\mathrm{SD} \pm 2.32$ ), paramedic students in this cohort are far more inclined to rely on experience rather than evidence. Item 3 produced a low mean (1.67) despite the scores for negatively worded item 17 heading 
Table 2 Practice style inventory mean item results

\begin{tabular}{|c|c|c|}
\hline & Mean & $\pm \mathbf{S D}$ \\
\hline \multicolumn{3}{|l|}{ Evidence versus experience questions } \\
\hline $\begin{array}{l}\text { I. Clinical experience is more important than } \\
\text { randomized controlled trials }\end{array}$ & 2.34 & 1.02 \\
\hline $\begin{array}{l}\text { 3. Evidence-based practice makes a lot of sense } \\
\text { to me }\end{array}$ & 1.67 & 0.69 \\
\hline $\begin{array}{l}\text { 9. Clinical experience is the most reliable way } \\
\text { to know what really works }\end{array}$ & 2.21 & 1.00 \\
\hline $\begin{array}{l}\text { 12. Patient care should be based where possible } \\
\text { on randomized controlled trials, rather than } \\
\text { on the opinion of respected authorities }\end{array}$ & 2.66 & 0.97 \\
\hline $\begin{array}{l}\text { 16. The best practice guidelines are based on the } \\
\text { results of randomized controlled trials }\end{array}$ & 2.49 & 0.80 \\
\hline $\begin{array}{l}\text { 17. Evidence-based practice is not very practical in } \\
\text { real patient care }\end{array}$ & 2.24 & 0.79 \\
\hline \multicolumn{3}{|l|}{ Nonconformity questions } \\
\hline $\begin{array}{l}\text { 2. I am comfortable practicing in ways different } \\
\text { than other health care professionals }\end{array}$ & 2.44 & 0.76 \\
\hline $\begin{array}{l}\text { 5. It is best to change the way I treat a certain } \\
\text { problem when my local colleagues are making } \\
\text { the same changes }\end{array}$ & 2.73 & 0.91 \\
\hline $\begin{array}{l}\text { 7. The opinions of respected authorities should } \\
\text { guide clinical practice }\end{array}$ & 2.32 & 0.80 \\
\hline II. I am often critical of accepted practices & 3.02 & 0.85 \\
\hline $\begin{array}{l}\text { 13. My colleagues consider me to be someone } \\
\text { who marches to my own drummer }\end{array}$ & 3.51 & 0.86 \\
\hline $\begin{array}{l}\text { 15. It is not prudent to practice out of step with } \\
\text { other health care professionals in my area }\end{array}$ & 3.02 & 0.78 \\
\hline \multicolumn{3}{|l|}{ Pragmatic concerns questions } \\
\hline $\begin{array}{l}\text { 4. I do not have the time to read up on every } \\
\text { practice decision }\end{array}$ & 3.55 & 0.77 \\
\hline $\begin{array}{l}\text { 6. I follow practice guidelines if they are not too } \\
\text { much hassle }\end{array}$ & 3.24 & 1.09 \\
\hline $\begin{array}{l}\text { 8. I am too busy taking care of patients to keep up } \\
\text { with the recent literature }\end{array}$ & 2.57 & 0.82 \\
\hline $\begin{array}{l}\text { 10. I am uncomfortable doing things differently from } \\
\text { the way I was trained }\end{array}$ & 3.05 & 0.97 \\
\hline $\begin{array}{l}\text { 14. I follow practice guidelines as long as they do not } \\
\text { interfere too much with the flow of patients }\end{array}$ & 3.13 & 0.91 \\
\hline
\end{tabular}

Abbreviation: SD, standard deviation.

towards the agreement end of the spectrum, highlighting some confusion over the benefit of EBP. Students express that EBP does not make much sense to them and they are unsure if it is very practical in patient care. This provides an opportunity for universities to impart knowledge of the importance and relevance of EBP. This may have a downstream positive impact on the acceptance and attitude towards KT.

The literature proposes that a subtotal score of 18 or above in the nonconformity subscale indicates that an individual is willing to go against the trends set by those around them. ${ }^{14}$ Though higher, the nonconformity mean score $16.8(\mathrm{SD} \pm 2.04)$ does not suggest a strong degree of confidence in practicing out of step with group norms, with students leaning slightly more towards conformist attitudes. However, interestingly, the question scoring the highest on average in this sub-scale was item 13 - "My colleagues consider me to be someone who marches to my own drummer" $-($ mean $=3.51, \mathrm{SD} \pm 0.86)$ while results for most of the other items were either roughly neutral or leaning more towards disagreement. This is surprising given that students are novices and should be more comfortable working within set guidelines considering their lack of experience. Perhaps this question, in the university context, plays on the personality or ego of some students, encouraging them to rank it more highly, which would require further investigation.

Students in the practicality subscale produced a mean score of $15.3(\mathrm{SD} \pm 2.07)$ where a subtotal score of greater than 14 indicates that the individual is concerned with pragmatic considerations. ${ }^{14}$ There was some agreement on items 4 - "I do not have the time to read up on every practice decision" - and 6 - "I follow practice guidelines if they are not too much hassle". Paramedic students in this study appear to have an appreciation of purely practical affairs, which includes time management and possibly the management of limited resources.

Recently, Snooks et a ${ }^{18}$ found that there were 96 evidence gaps related to current out-of-hospital policy, management, clinical practice, and service delivery in the United Kingdom. Some authors suggest that the time lag between the availability of research evidence and its use in clinical practice can be anywhere from 8 to 30 years. ${ }^{5,19-22}$ The curriculum provided at Monash University's Paramedic Department includes, as part of its coursework and curriculum, an evidence-based approach to clinical practice. Given this, it would be reasonable to expect the results to reflect a greater level of confidence in students' use of scientific evidence; however, this was not the case based on these self-reported results. Perhaps our study results, as with previous studies involving various health care groups, may be at least partially explained by the general admission of a lack of understanding of evidence-based practice. The lack of confidence in understanding, interpreting research findings, or confidence in translating evidence into practice may result in a preference for relying on direction from senior clinicians and "experts". Future research utilizing a mixed methods approach would be useful in examining these views in more detail.

The statistically significant difference between sexes on the evidence versus experience subscale suggests that females have an increased tendency towards belief in scientific evidence over experience as the best source of knowledge. In truth, it is not known to what the observed difference between sexes on the weighting given to scientific evidence can be 
attributed, but it is perhaps worthy of further exploration. The same is true of the increasing degree of comfort with nonconformity in line with progression through study and increasing age. Perhaps this may be linked to accumulation of life experience or previous work roles, and this is also worthy of further investigation.

\section{Study limitations}

The use of convenience samples of students from one university may not be representative of the student population as a whole or generalizable to other universities. Future studies would do well to involve larger sample sizes, so as to permit a more thorough estimation of attitudes amongst the paramedic profession, including practicing paramedics. Additionally, respondents who did volunteer to participate in the survey may be more academically inclined or may be proactive learners, which may also introduce bias into the sample.

\section{Future implications}

A larger sample size across multiple institutions including qualitative data, and a study design to capture changing attitudes over time, will prove more insightful. The observed difference between sexes on the weighting given to scientific evidence, and the increasing degree of comfort with nonconformity in line with progression through study and increasing age, is worthy of further exploration.

The application of a psychometric instrument such as the PSI to help identify barriers to KT amongst paramedics has important implications during review of the methods being used to teach undergraduate paramedic students. It can also be used to promote improved practice change and timely implementation of guidelines in the postgraduate population.

\section{Conclusion}

This study found that paramedic students are far more inclined to rely on experience rather than evidence as the best source of information showing that, despite being trained in EBP, students still do not appear to have much faith in it. This indicates that there is opportunity to improve the way that EBP is taught to students and its coherence throughout the curriculum. Since improved KT facilitates the expedient uptake of innovation and research into clinical practice, it is an issue that cannot be ignored. Improved understanding of the distribution of different practice style traits among the paramedic profession as a whole is an important step in helping to bridge KT gaps. Only when paramedics understand EBP will they accept and participate in KT. Further investigation is warranted in order to better understand barriers and facilitate improved uptake of evidence-based research into clinical practice and, ultimately, improve patient outcomes. The next generations of paramedics are in as good a position as any to be agents in effecting such a change.

\section{Acknowledgments}

We would like to thank the students for participating and completing the questionnaires.

The authors alone are responsible for the content and writing of this article.

\section{Disclosure}

The authors report no conflicts of interest in this work.

\section{References}

1. Kohn L, Corrigan J, Donaldson M. To Err is Human: Building a Safer Health System. Washington (DC): National Academy Press; 2002.

2. Fineout-Overholt E, Melnyk BM, Schultz A. Transforming health care from the inside out: advancing evidence-based practice in the $21 \mathrm{st}$ century. J Prof Nurs. 2005;21(6):335-344.

3. Davis D, Evans M, Jadad A, et al. The case for knowledge translation: shortening the journey from evidence to effect. BMJ. 2003;327(7405): $33-35$.

4. Madon T, Hofman KJ, Kupfer L, Glass RI. Public health. Implementation science. Science. 2007;318:1728-1729.

5. McGlynn EA, Asch SM, Adams J, et al. The quality of health care delivered to adults in the United States. N Engl J Med. 2003;348(26): 2635-2645.

6. Majumdar SR, McAlister FA, Furberg CD. From knowledge to practice in chronic cardiovascular disease: a long and winding road. $J$ Am Coll Cardiol. 2004;43(10):1738-1742.

7. Graham ID, Logan J, Harrison MB, et al. Lost in knowledge translation: time for a map? J Contin Educ Health Prof. 2006;26(1):13-24.

8. Sudsawad P. Knowledge Translation: Introduction to Models, Strategies and Measures. Austin: Southwest Educational Development Laboratory, National Center for the Dissemination of Disability Research; 2007. Available from: http://www.ktdrr.org/ktlibrary/articles_pubs/ktmodels/ index.html. Accessed April 11, 2012.

9. Straus SE, Tetroe JM, Graham ID. Knowledge translation is the use of knowledge in health care decision making. J Clin Epidemiol. 2011;64(1):6-10.

10. Straus SE, Tetroe J, Graham I. Defining knowledge translation. CMAJ. 2009;181(3-4):165-168.

11. About knowledge translation and commercialization [webpage on the internet]. Ottawa: Canadian Institutes of Health Research [updated May 15, 2013]. Available from: http://www.cihr-irsc.gc.ca/e/29418.html. Accessed February 16, 2013.

12. World Health Organization. Knowledge Translation on Aging and Health: A framework for policy and development 2012. http://www. who.int/ageing/publications/knowledge_translation_en.pdf. Accessed April 14, 2013.

13. Wyszewianski L, Green LA. Strategies for changing clinicians' practice patterns: a new perspective. J Fam Pract. 2000;49(5):461-464.

14. Green LA, Gorenflo DW, Wyszewianski L; Michigan Consortium for Family Practice Research. Validating an instrument for selecting interventions to change physician practice patterns. J Fam Pract. 2002;51(11):938-942. 
15. Hadouda S, Laroui HR, Lemay A, et al. Practice style traits of student occupational therapists and physical therapists. Can J Occup Ther. 2009;76(2):98-106.

16. Korner-Bitensky N, Menon-Nair A, Thomas A, Boutin E, Arafah AM. Practice style traits: do they help explain practice behaviours of stroke rehabilitation professionals? J Rehabil Med. 2007;39(9): 685-692.

17. Ball L. Setting the scene for the paramedic in primary care: a review of the literature. Emerg Med J. 2005;22(12):896-900.

18. Snooks H, Evans A, Wells B, et al. What are the highest priorities for research in emergency prehospital care? Emerge Med J. 2009;26(8):549-550.
19. Bigham BL, Aufderheide TP, Davis DP, et al. Knowledge translation in emergency medical services: a qualitative survey of barriers to guideline implementation. Resuscitation. 2010;81(7):836-840.

20. Bigham BL, Dainty KN, Scales DC, Morrison LJ, Brooks SC. Predictors of adopting therapeutic hypothermia for post-cardiac arrest patients among Canadian emergency and critical care physicians. Resuscitation. 2010;81(1):20-24.

21. Kennedy J, Green RS, Stenstrom R; CAEP Critical Care Committee. The use of induced hypothermia after cardiac arrest: a survey of Canadian emergency physicians. CJEM. 2008;10(2):125-130.

22. LaRosa JC, He J, Vupputuri S. Effect of statins on risk of coronary disease. JAMA. 1999;282(24):2340-2346.

\section{Publish your work in this journal}

Advances in Medical Education and Practice is an international, peerreviewed, open access journal that aims to present and publish research on Medical Education covering medical, dental, nursing and allied health care professional education. The journal covers undergraduate education, postgraduate training and continuing medical education including emerging trends and innovative models linking education, research, and health care services. The manuscript management system is completely online and includes a very quick and fair peer-review system. Visit http://www.dovepress.com/testimonials.php to read real quotes from published authors.

Submit your manuscript here: http://www.dovepress.com/advances-in-medical-education-and-practice-journal 